\title{
GEOMETRIC OPTIMIZATION OF A BEAM DETECTOR FOR A WIM SYSTEM
}

\author{
Aleksander Nieoczym ${ }^{1}$, Kazimierz Drozd ${ }^{2}$, Andrzej Wójcik ${ }^{3}$ \\ 1 Lublin University of Technology, Ul. Nadbystrzycka 36, 20-618 Lublin, Poland, e-mail: a.nieoczym@pollub.pl \\ 2 Department of Materials Engineering, Lublin University of Technology, ul. Nadbystrzycka 36, 20-618 Lublin, \\ Poland, e-mail: k.drozd@pollub.pl \\ ${ }^{3}$ Departament of Machine Design and Mechatronics, Lublin University of Technology, ul. Nadbystrzycka 36, \\ 20-618 Lublin, Poland, e-mail: a.wojcik@pollub.pl)
}

Received: 2018.01.02 Accepted: 2018.07.01 Published: 2018.09.01

\begin{abstract}
Weigh-in-Motion (WIM) systems are designed for weighing vehicles driving across a measurement site. Because during measurements the vehicle has to come in physical contact with the components of the system, WIM systems always use built-in sensors installed in road pavement. Each WIM system consists of force sensors placed in one, two or even several lines, perpendicular to the direction of traffic. The idea behind WIM systems is to measure the dynamic loads that the wheels of a moving vehicle exert on the road surface and, on this basis, to estimate static wheel loads as well as gross vehicle weight.
\end{abstract}

Keywords: FEM, BEAM, weigh-in-motion, deflection of the beam, fibre optic sensor

\section{INTRODUCTION}

Weigh-in-Motion (WIM) systems are designed for weighing vehicles driving across a measurement site. Because during measurements the vehicle has to come in physical contact with the components of the system, WIM systems always use built-in sensors installed in road pavement. Each WIM system consists of force sensors placed in one, two or even several lines, perpendicular to the direction of traffic.

\section{Literature reviews}

The idea behind WIM systems is to measure the dynamic loads that the wheels of a moving vehicle exert on the road surface and, on this basis, to estimate static wheel loads as well as gross vehicle weight. The accuracy of WIM measurements is determined by the measuring conditions, including:

- vehicle speed,

- quality of the road pavement in which the WIM system is installed [12],

- properties of the force sensors used [5, 10],
- calibration procedure and frequency of system calibration $[1,9,8,9,11,14]$,

- algorithm used for estimating static load and gross vehicle weight [13].

WIM systems are divided with respect to design and functionality criteria into two types: multi-sensor and classic mechanical systems. The more advanced and more complex Multi-Sensor WIM (MS WIM) systems [3, 4], are equipped with cameras, which make it possible to collect additional information regarding the fixed and variable parameters of road traffic. The fixed parameters are characteristics such as vehicle class, registration number, number of axles, distances between individual axles, distances between extreme axles, and vehicle length. The variable parameters include time of vehicle arrival at the measurement point, vehicle speed, direction of movement, and the number of lane in which the vehicle was detected.

An MS-WIM system installed in a road lane allows automatic measurement of vehicle parameters, in particular axle loads and gross weight, without imposing significant speed limits. MS-WIM is a 
multi-configuration system based on inductive loop systems with an optionally installed axle detector and polymer or quartz force sensors. The force sensors are distributed evenly along the measuring area. Each pair of force sensors is surrounded by an inductive loop, thus creating a dual-sensor WIM subsystem. Each such subsystem cooperates with its own signal conditioning system, an a/d converter and a processor system that controls the acquisition of measurement signals, their pre-processing and transmission to the host system. The system is designed for measuring and determining traffic characteristics such as traffic density, vehicle flow, lane occupancy, average speed, and time distances between vehicles [2].

Mechanical WIM systems use piezoelectric and strain gauge sensors as vehicle-load-converting elements. Piezoelectric sensors are mounted directly on a metal plate or beam ("bending plate"), which is subjected to vehicle axle loads. Axle loads and vehicle weights can also be measured using detectors that have the form of a platform supported on mechanical elements (columns, beams), the so-called 'load cells', which are equipped with strain gauges for measuring deflection of the cells. The main advantage of load cells is their high measuring accuracy. They reach an accuracy of $2 \%$ during static measurements. The detectors used in dynamic conditions achieve an accuracy of $\pm 10 \%$ for gross weight measurements and approx. $\pm 15 \%$ for single-axle load measurements. Often, strain gauge scales are used as low-speed scales (vehicle speed up to 6 $\mathrm{km} / \mathrm{h}$ ); they have an accuracy similar to stationary weights. The nominal weighing capacity of this type of scales is up to 20 tons/axle. [15, 16]

\section{Purpose of scientific and research works}

The WIM measuring systems described above are used as dynamic in-motion scales designed to monitor the weight of vehicles with a maximum permissible gross weight in the range from 3,500 $\mathrm{kg}$ to $36,000 \mathrm{~kg}$. However, apart from weighing vehicles, it is often also necessary to simultaneously analyse what types of vehicles (by number of wheels, e.g. two-wheelers, four wheelers, etc.) are participating in traffic. This type of analysis involves not only the measurement of vehicle weight but also qualitative detection. Such data are mainly collected and analysed in urban traffic, in which information on traffic volume, lane occupancy or the number of vehicles waiting to en- ter an intersection are important from the point of view of ensuring continuous, smooth traffic flow. Defined in this way, the task of a WIM system is to measure the weight of vehicles moving on a road and to detect whether they are motorcycles, passenger cars, heavy goods vehicles, or other. Systems with inductive loops, commonly used in cities, enable the collection of traffic volume data, but they do not allow measurement of vehicle weight within the range given above $(3,500$ $\mathrm{kg}$ to $36,000 \mathrm{~kg}$ ).

This article presents a design of a WIM system in which the detector is a beam with Bragg grating optical fibre sensors glued on it. Fibre Bragg gratings (FBG) are wavelength shift sensors, in which the wavelength of light shifts under the influence of the parameter measured.

A fibre optic sensor was used because it offers an array of advantages:

- high sensitivity to vertical forces (about 10\% change in light intensity at loads exerted by an average-sized passenger vehicle),

- measurement of constant loads and loads variable in time,

- robustness to electromagnetic interference systems with FBG sensors can be installed in the vicinity of high voltage power lines or railway, tram and trolleybus electric traction,

- high mechanical strength (long service life), resistance to corrosion, reliability and repeatability of measurements,

- it can be used on stations that do not have an electric power supply; the signal from the sensor can be sent through a fibre-optic cable at a distance of up to $2 \mathrm{~km}$ from the measuring point.

\section{CALCULATION METHODOLOGY}

\section{Design of the beam detector}

The system was designed to detect the presence and measure the weight of various vehicles ranging from motorcycles (single-truck vehicles) to trucks. The extreme values of permissible vehicle weight were assumed to be $250 \mathrm{~kg}$ and 10,000 $\mathrm{kg}$. It was assumed that in a two-wheeled vehicle, the tyre force was $1000 \mathrm{~N}$. A single axle of a truck with a gross vehicle weight $\mathrm{m}=10,000 \mathrm{~kg}$ exerts a force of $60000 \mathrm{~N}$.

FBG sensors with a length of $15 \mathrm{~mm}$ and a diameter $\phi 2$. The maximum relative elongation 
must not exceed $\varepsilon_{\max }=0.003(0.3 \%)$, with the minimum value $\varepsilon_{\min }=0.000015(0.0015 \%)$. Maximum elongation of the sensor $u=0.045 \mathrm{~mm}$.

The following design restrictions were defined for the beam:

- Stresses in the beam caused by the weight of a heavy goods vehicle may not exceed the permissible stresses.

- The maximum relative elongation of the beam at the sensor mounting site caused by the weight of the car may not cause the maximum relative elongation of the sensor to be exceeded.

- The measuring system must be able to detect the presence and measure the weight of a motorcycle in motion at any point along the width of the lane.

Based on the above assumptions, four cases of loading of the beam were considered which were important from the point of view of beam strength and the possibility of registering deformations (Table 1). Case $2 b$ is related to permissible beam stresses and the maximum elongation of the sensor. Case 1a is associated with the minimum beam deformations that a fibre optic sensor can register.

\section{Analytical strength calculations of the beam}

In cases in which a beam is loaded with the weight of a motorcycle, the placement of the fibre optic sensors on the beam is important. They must be glued in regions of maximum beam deflection.
The crux of the problem, therefore, is to calculate the value of the bending moment generated in the beam under the influence of a single-track vehicle and then to calculate whether the relative deformation of the beam under the influence of this moment can be registered by a fibre optic sensor.

The bending moment determined in any section defined by the coordinate variable $x$ (Fig. 1):

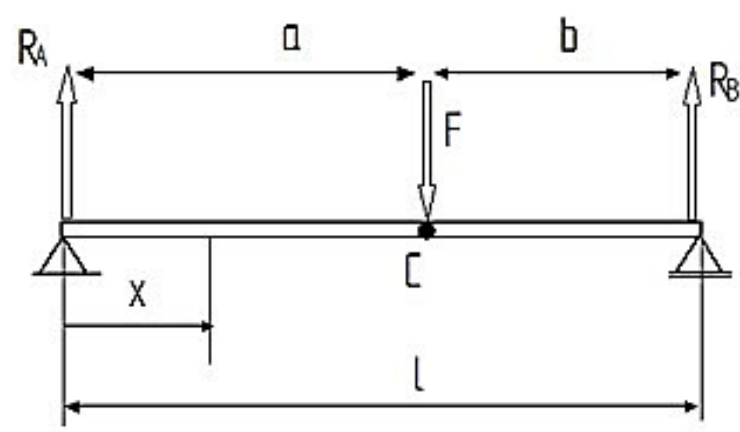

Fig. 1. Schematic of beam loaded with a double-track vehicle: $\mathrm{x}$ - variable defining the distance from the support to the centre of the wheel, F - motorcycle tyre force, $\mathrm{c}$ - point of application of the force (the centre of the wheel of the motorcycle), $R_{A}, R_{B}$ - reactions on the supports, 1 - length of the beam

Section I:

$$
M_{g}=\frac{F b}{l} x \quad 0 \leq x \leq a
$$

Section II:

$$
M_{g}=\frac{F b}{l} x-F(x-a) \quad a \leq x \leq l
$$

assuming $w_{\mathrm{I}}$ and $w_{\mathrm{II}}$ are deflections in these sections, we get equations:

Table 1. Cases of beam loading

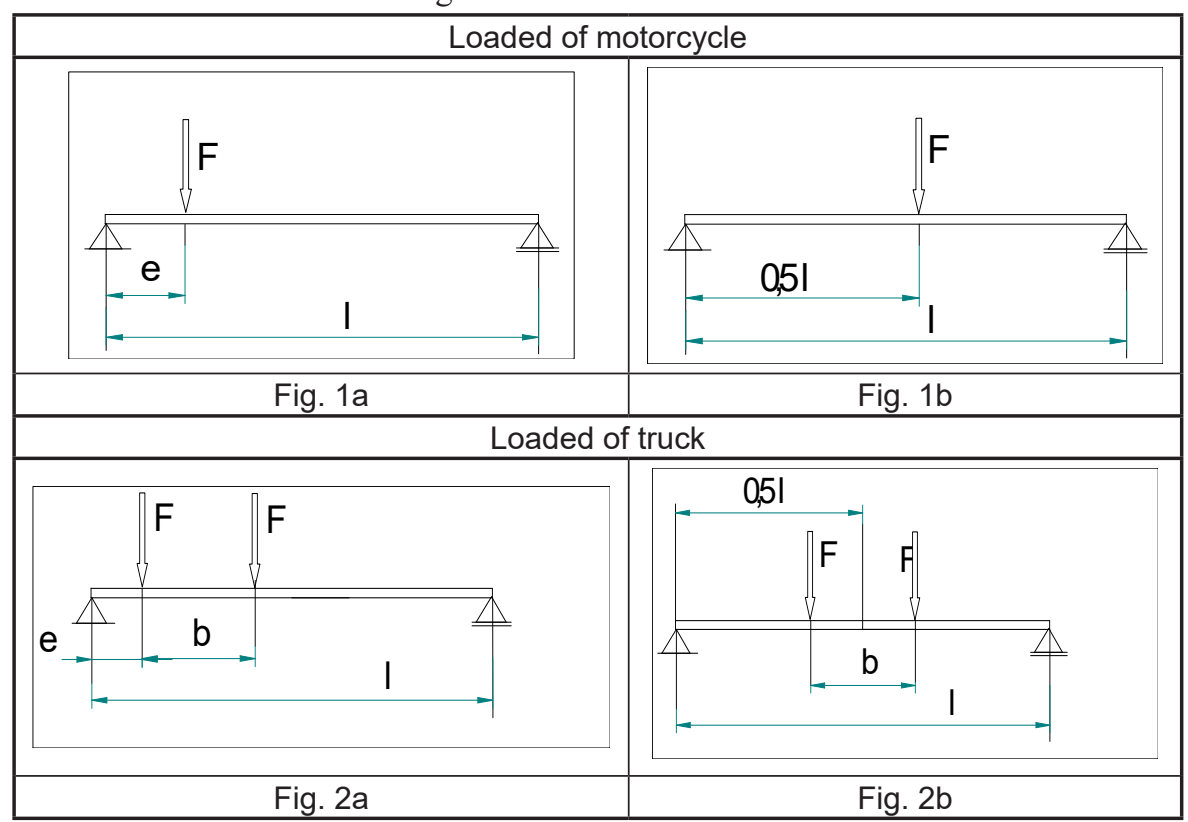




$$
\begin{gathered}
E J_{y} w_{I}^{\prime \prime}=\frac{F b x}{l} \\
E J_{y} w_{I I}^{\prime \prime}=\frac{F b x}{l}-P x+P a
\end{gathered}
$$

By using integration, we get the following solution:

$$
w_{c}=\left(w_{I}\right)_{x=a}=\left(w_{I I}\right)_{x=a}=-\frac{P a^{2} b^{2}}{3 E J_{y} l}(5)
$$

Maximum deflection $f=\left|w_{\max }\right|$ :

When $a>0.51$ then $w_{\max }$ is in section I and the corresponding coordinate has the value:

$$
x_{I}=\sqrt{\frac{1}{3}\left(l^{2}-b^{2}\right)}
$$

And maximum deflection is:

$$
f=\left|w_{\max }\right|=\frac{F b\left(l^{2}-b^{2}\right)^{\frac{3}{2}}}{9 \sqrt{3} E J_{y} l}
$$

The $x$ coordinate described by formula (6) does not deviate much from the value of $0.5 l$. Even when $\mathrm{b} \rightarrow 0$ :

Then:

$$
x_{1} \rightarrow \frac{l}{\sqrt{3}}
$$

$$
x_{1}-\frac{l}{2} \approx 0,08 l
$$

This makes the difference: $w_{\max }-w_{x=0,5 l}$ small, and in the limit case, when $\mathrm{b} \rightarrow 0$ then:

$$
\left|w_{\max }-w_{x=0,5 l}\right| \leq 2,5 \%\left|w_{\max }\right|
$$

\section{Calculation results}

Whether the beam can be used as a signal transmitter for optical fibre sensors is determined by its deflection under the influence of a passing single-track (low weight) vehicle Deflection of the beam, uniquely defined by maximum deflection $f$, is associated with its deflection line. Maximum deflection calculated with the formulas (8) and (9) indicates that the fibre optic sensors should be placed symmetrically at a distance of $240 \mathrm{~mm}$ from the centre of the beam at points $\mathrm{P} 1, \mathrm{P} 2$, and $\mathrm{P} 3$ (Fig. 2).

FEM strength calculations using Abaqus software were conducted. The results of modeling points $\mathrm{P} 1, \mathrm{P} 2, \mathrm{P} 3$ are shown in Table $2-5$.

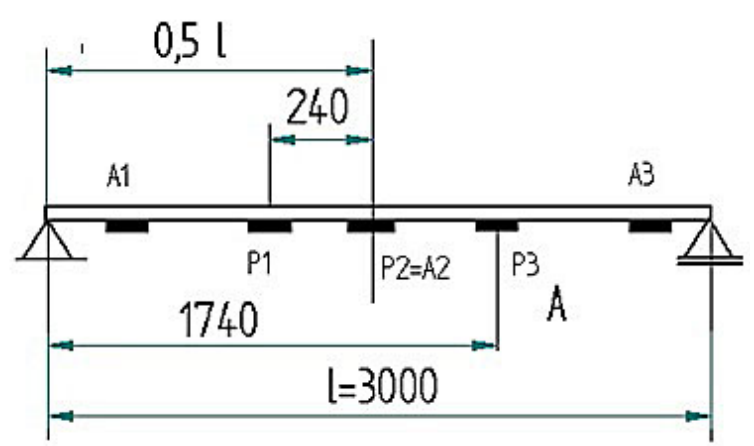

Fig. 2. Location of sensors: P1, P2, P3 - placement points for fibre optic sensors determined in beam deflection calculations, A1, A2, A3 - sensor placement points resulting from geometric optimization of the beam

Table 2. Results of modelling FEM, case 1a (Table 1)

\begin{tabular}{|c|c|c|c|}
\hline Point & $\begin{array}{c}\text { Stresses in the direction of the } \\
\text { beam axis }\left[\mathrm{N} / \mathrm{mm}^{2}\right]\end{array}$ & $\begin{array}{c}\text { Deflection of the beam } \\
{[\mathrm{mm}]}\end{array}$ & Deformation [xE-5] \\
\hline P1 & 1.31 & 0.135 & 0.62 \\
\hline P2 & 1.09 & 0.131 & 0.52 \\
\hline P3 & 0.95 & 0.121 & 0.45 \\
\hline
\end{tabular}

Table 3. Results of modelling FEM, case 1b (Table 1)

\begin{tabular}{|c|c|c|c|}
\hline Point & $\begin{array}{c}\text { Stresses in the direction of the } \\
\text { beam axis }\left[\mathrm{N} / \mathrm{mm}^{2}\right]\end{array}$ & $\begin{array}{c}\text { Deflection of the beam } \\
{[\mathrm{mm}]}\end{array}$ & Deformation [xE-5] \\
\hline P1 & 5.70 & 0.51 & 2.69 \\
\hline P2 & 6.29 & 0.52 & 2.95 \\
\hline P3 & 5.70 & 0.51 & 2.69 \\
\hline
\end{tabular}

Table 4. Results of modelling FEM, case 2a (Table 1)

\begin{tabular}{|c|c|c|c|}
\hline Point & $\begin{array}{c}\text { Stresses in the direction of the } \\
\text { beam axis }\left[\mathrm{N} / \mathrm{mm}^{2}\right]\end{array}$ & $\begin{array}{c}\text { Deflection of the beam } \\
{[\mathrm{mm}]}\end{array}$ & Deformation [xE-5] \\
\hline P1 & 126.26 & 13.77 & 59.82 \\
\hline P2 & 136.50 & 14.34 & 65.00 \\
\hline P3 & 147.24 & 14.08 & 70.09 \\
\hline
\end{tabular}


Table 5. Results of modelling FEM, case 2b (Table 1)

\begin{tabular}{|c|c|c|c|}
\hline Point & $\begin{array}{c}\text { Stresses in the direction of the } \\
\text { beam axis }\left[\mathrm{N} / \mathrm{mm}^{2}\right]\end{array}$ & $\begin{array}{c}\text { Deflection of the beam } \\
{[\mathrm{mm}]}\end{array}$ & Deformation [xE-5] \\
\hline P1 & 136.49 & 14.50 & 64.70 \\
\hline P2 & 136.50 & 14.94 & 64.70 \\
\hline P3 & 136.49 & 14.55 & 64.70 \\
\hline
\end{tabular}

Results on the correctness of modelling:

- Maximum stress produced in the beam by a vehicle's weight does not exceed permissible stress.

- Deflection of the beam under the weight of a motorcycle is too small to be registered by a fibre optic sensor.

\section{Optimization of the beam shape}

Due to the fact that the beam was characterized by excessive stiffness which made it impossible to identify a single-track vehicle, the shape of the beam was optimized. The optimization involved introduction of local changes in the crosssection of the existing beam. Longitudinal holes, $100 \mathrm{~mm}$ wide and $250 \mathrm{~mm}$ long, were made in the lower plane of the beam (Fig. 3). Two sensors were glued inside the beam along the longitudinal edge of the hole at a distance of $384 \mathrm{~mm}$ from the end of the beam, $20 \mathrm{~mm}$ from the edge of the hole - points A1 and A3. A third sensor was attached to the beam at its mid-length - point A2 (equivalent to point $\mathrm{P} 2$ ). The advantage of the change in the geometry of the beam is that the sensors and connecting cables inside the beam are protected

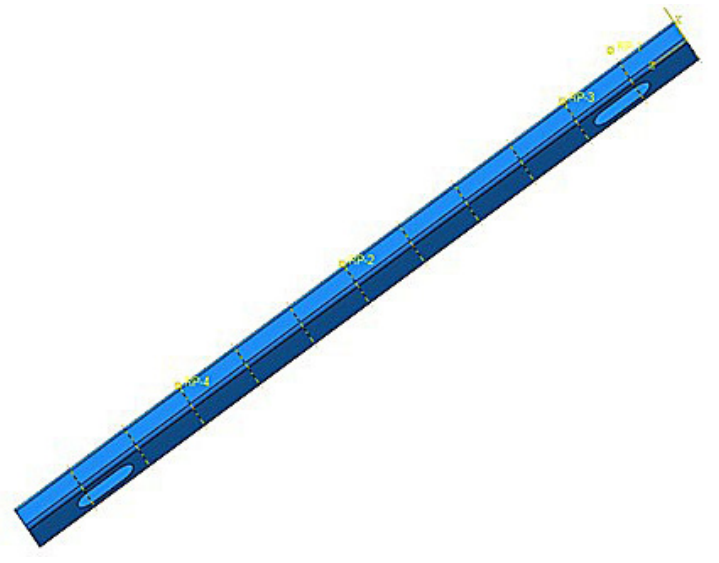

Fig. 3. Beam after the process of geometric optimization

from damage. Tables 6-8 show the results of FEM strength analysis. The results of modeling are presented in Figures 4-15.

\section{CONCLUSIONS}

Applications for optimization of geometric beam detector with the use of CAD:

1. Parametric models describing the influence of vehicle tyre force depending on the location of

Table 6. Results of modelling FEM, beam with holes, case 1a (Table 1)

\begin{tabular}{|c|c|c|c|}
\hline Point & $\begin{array}{c}\text { Stresses in the direction of the } \\
\text { beam axis }\left[\mathrm{N} / \mathrm{mm}^{2}\right]\end{array}$ & $\begin{array}{c}\text { Deflection of the beam } \\
{[\mathrm{mm}]}\end{array}$ & Deformation [xE-5] \\
\hline A1 & 3.90 & 0.079 & 1.83 \\
\hline P1 & 1.31 & 0.140 & 0.62 \\
\hline P2 = A2 & 1.09 & 0.135 & 0.52 \\
\hline P3 & 0.95 & 0.125 & 0.45 \\
\hline A3 & 0.62 & 0.047 & 0.29 \\
\hline
\end{tabular}

Table 7. Results of modelling FEM, beam with holes, case 1b (Table 1)

\begin{tabular}{|c|c|c|c|}
\hline Point & $\begin{array}{c}\text { Stresses in the direction of the } \\
\text { beam axis }\left[\mathrm{N} / \mathrm{mm}^{2}\right]\end{array}$ & $\begin{array}{c}\text { Deflection of the beam } \\
{[\mathrm{mm}]}\end{array}$ & Deformation [xE-5] \\
\hline A1 & 3.66 & 0.204 & 1.72 \\
\hline P1 & 5.70 & 0.52 & 2.70 \\
\hline P2 = A2 & 6.29 & 0.53 & 2.95 \\
\hline P3 & 5.70 & 0.52 & 2.70 \\
\hline A3 & 3.70 & 0.209 & 1.74 \\
\hline
\end{tabular}


Table 8. Results of modelling FEM, beam with holes, case 2a (Table 1)

\begin{tabular}{|c|c|c|c|}
\hline Point & $\begin{array}{c}\text { Stresses in the direction of the } \\
\text { beam axis }\left[\mathrm{N} / \mathrm{mm}^{2}\right]\end{array}$ & $\begin{array}{c}\text { Deflection of the beam } \\
{[\mathrm{mm}]}\end{array}$ & Deformation [xE-5] \\
\hline A1 & 161.35 & 6.13 & 75.30 \\
\hline P1 & 125.63 & 9.92 & 59.82 \\
\hline P2 = A2 & 136.50 & 14.68 & 64.67 \\
\hline P3 & 147.24 & 14.11 & 70.09 \\
\hline A3 & 183.68 & 6.41 & 86.31 \\
\hline
\end{tabular}

Table 9. Results of modelling FEM, beam with holes, case 2b (Table 1)

\begin{tabular}{|c|c|c|c|}
\hline Point & $\begin{array}{c}\text { Stresses in the direction of the } \\
\text { beam axis }\left[\mathrm{N} / \mathrm{mm}^{2}\right]\end{array}$ & $\begin{array}{c}\text { Deflection of the beam } \\
{[\mathrm{mm}]}\end{array}$ & Deformation [xE-5] \\
\hline A1 & 187.46 & 6.30 & 87.53 \\
\hline P1 & 136.49 & 14.83 & 65.00 \\
\hline P2 = A2 & 136.49 & 15.27 & 65.00 \\
\hline P3 & 136.49 & 14.88 & 65.00 \\
\hline A3 & 186.90 & 6.53 & 87.26 \\
\hline
\end{tabular}

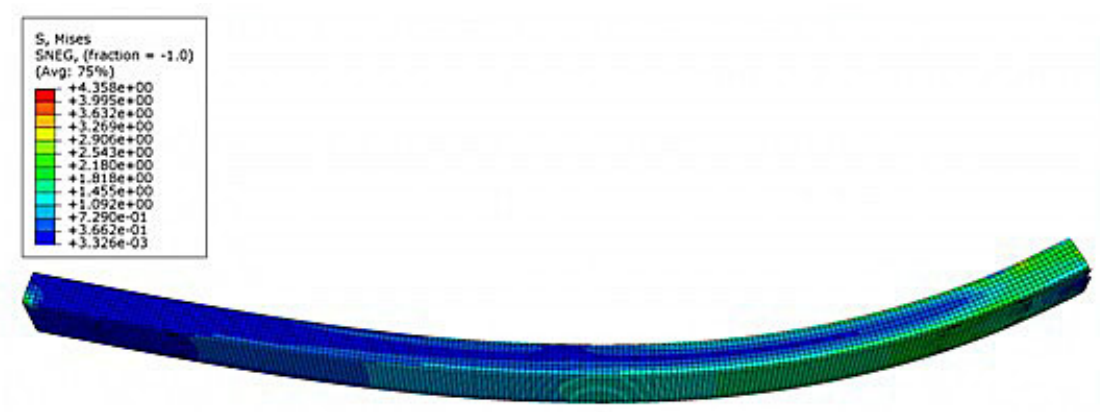

Fig. 4. Reduced stresses, case 1a

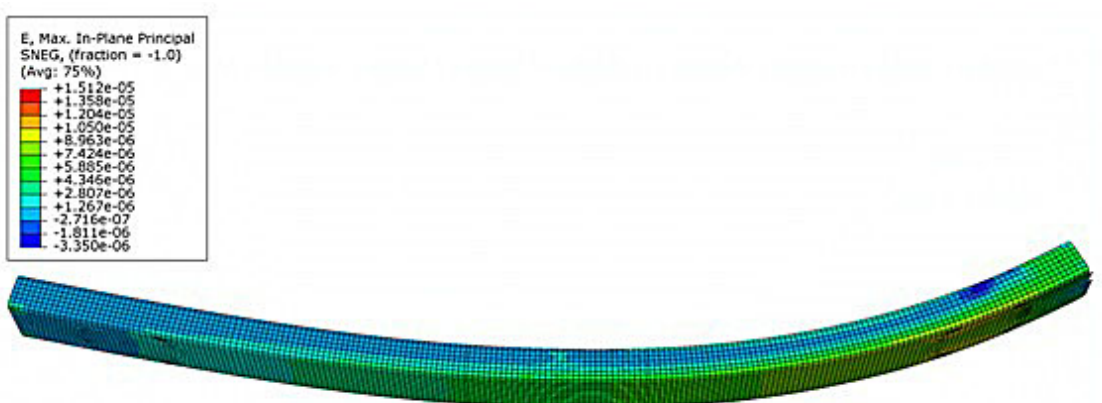

Fig. 5. Deformation, case 1a

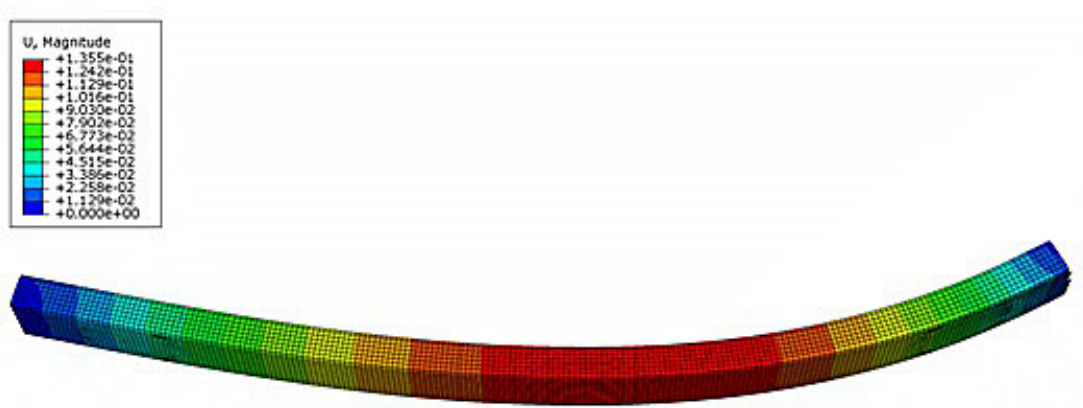

Fig. 6. Deflection, case 1a 

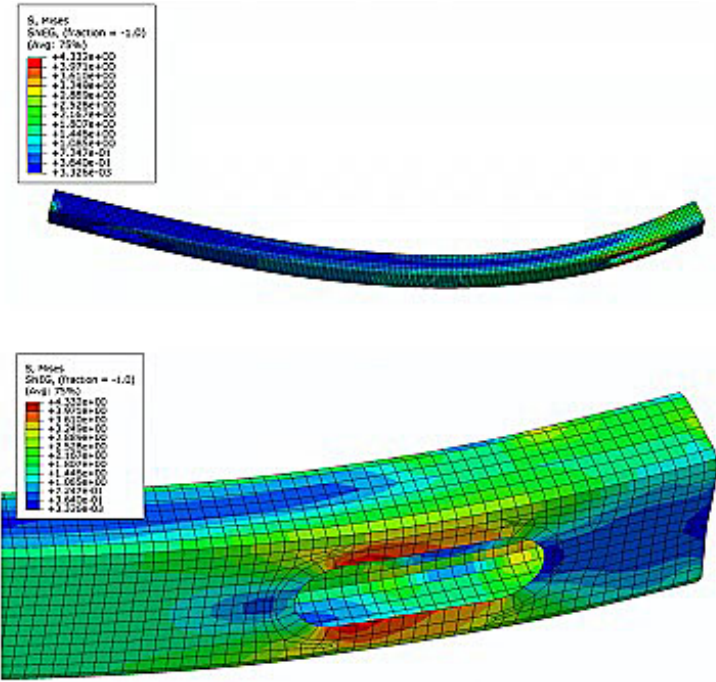

Fig. 7. Reduced stresses, case 1a, beam after the process of geometric optimization
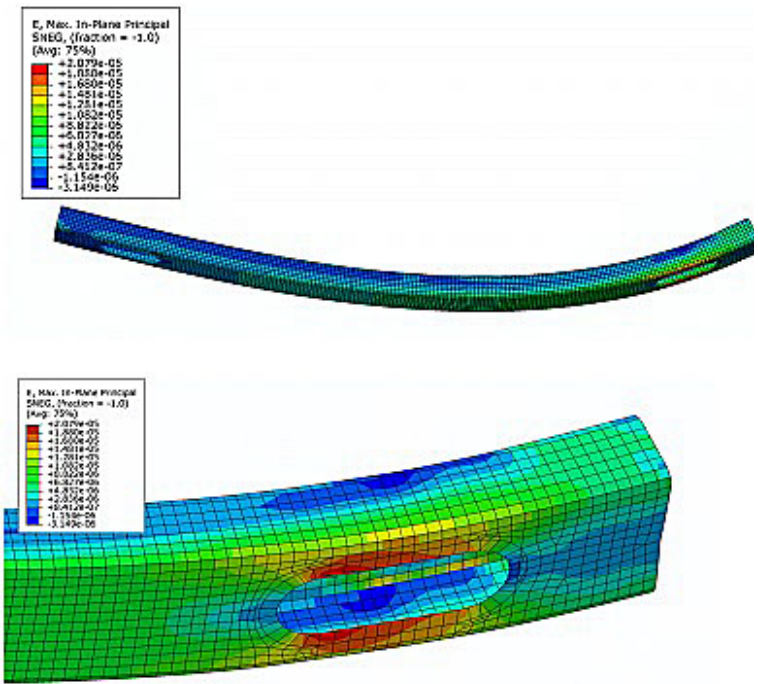

Fig. 8. Deformation, case 1a, beam after the process of geometric optimization
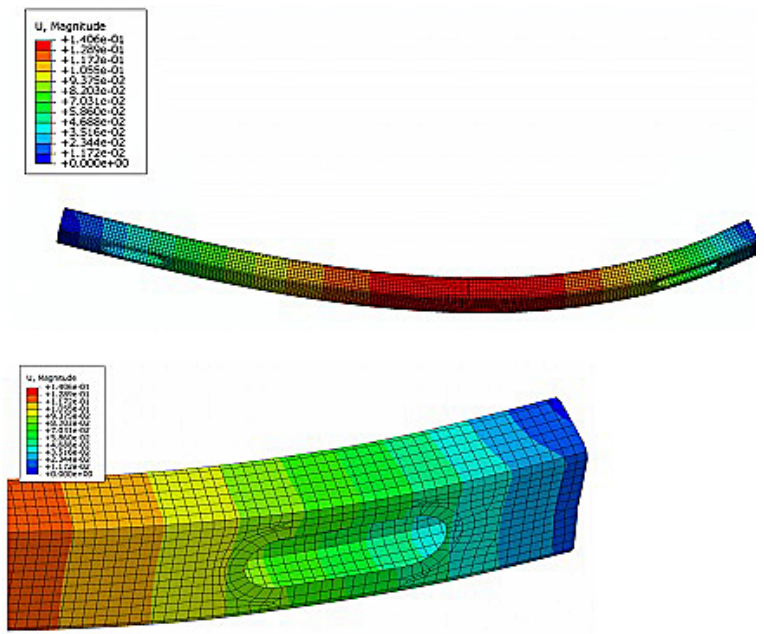

Fig. 9. Deflection, case 1a, beam after the process of geometric optimization

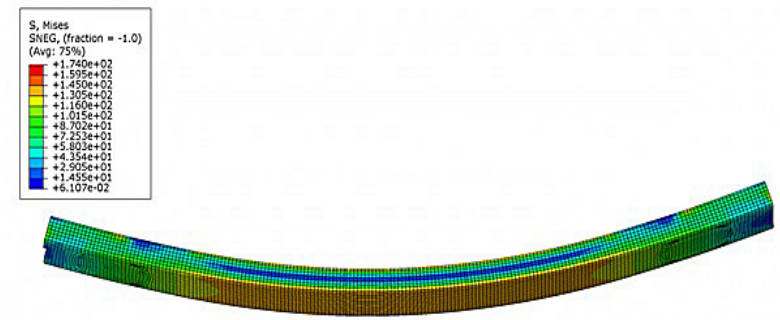

Fig. 10. Reduced stresses, case $2 b$

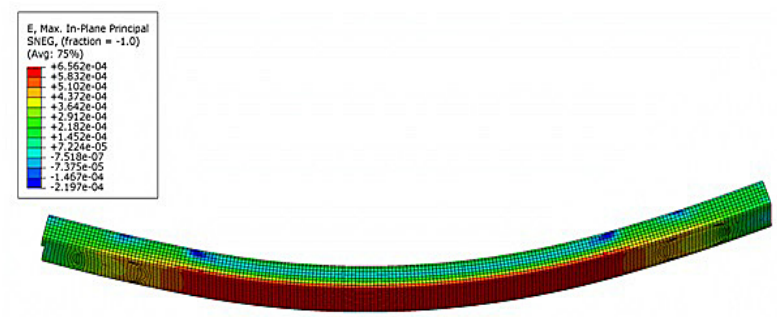

Fig. 11. Deformation, case $2 b$
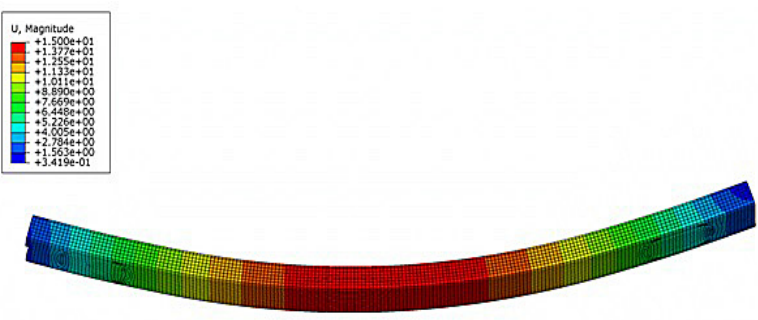

Fig. 12. Deflection, case $2 b$
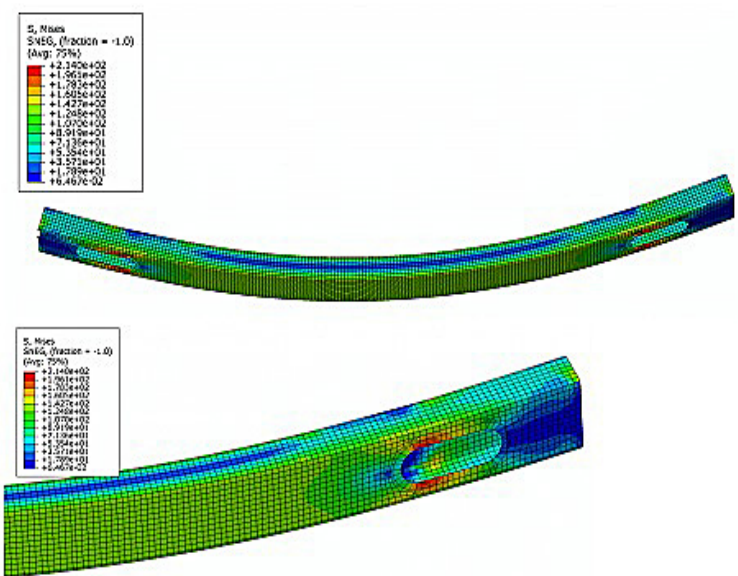

Fig. 13. Reduced stresses, case $2 b$, beam after the process of geometric optimization 

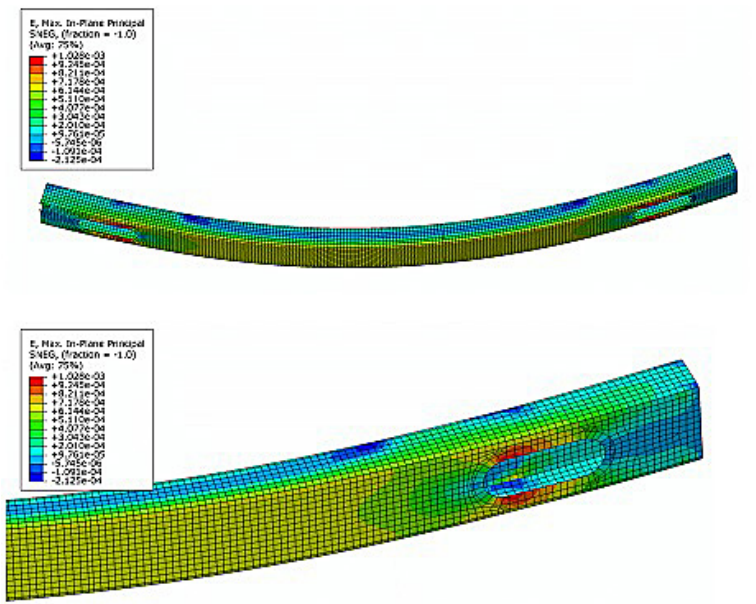

Fig. 14. Deformation, case $2 b$, beam after the process of geometric optimization

the wheel on the detector beam of a WIM system were developed and verified.

2. The fibre optic sensors were located on the beam so that they could register beam deformations produced by the weight of a singletrack vehicle.

3. Parametric models were used to optimize the shape of the beam so that it could be used to measure the weight of vehicles within the permissible total weight from $250 \mathrm{~kg}$ to $10,000 \mathrm{~kg}$ and to detect certain road traffic parameters.

4. The selected shape of the holes reducing the stiffness of the beam did not lead to exceed of the permissible stresses in any cross-section of the beam under the weight of the truck, the reduced stresses have the value $\sigma_{\text {zred }}=187 \mathrm{MPa}$ and do not exceed the yield point. The holes created increase the flexibility of the beam and enable registration of the weight and presence of the motorcycle. The beam deformation value takes the value of $\varepsilon=1,83 \mathrm{e}^{-5}$ with the minimum strain value possible to register by a fiber optic sensor equal to $\varepsilon=1.5 \mathrm{e}^{-5}$

Conclusions regarding further model tests

5. The next research problem should be the optimization of the shape of the beam supports in order to limit the deformation of the beam ends under the supports.

Applications regarding the use of a beam detector

6. The article presents the concept of constructing a beam detector of the WMS system, which can be used as a replacement for Multi Sensor Weigh in Motion (MS-WIM) systems

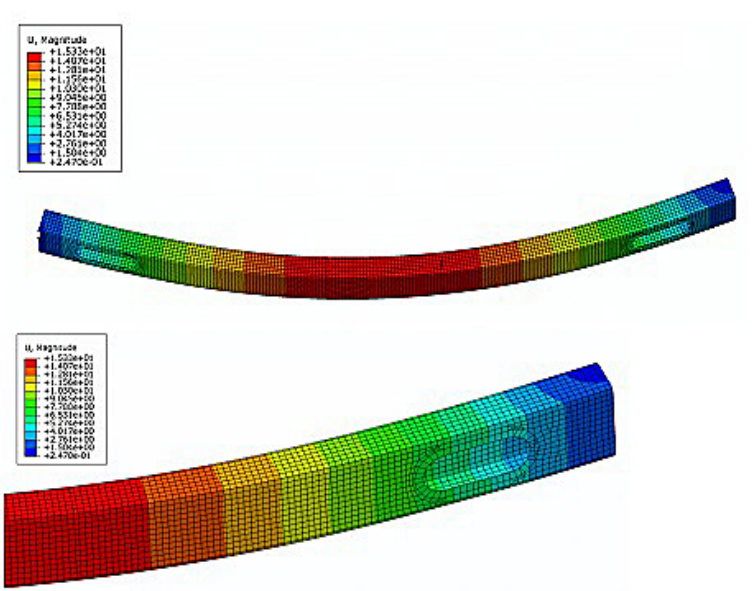

Fig. 15. Deflection, case $2 b$, beam after the process of geometric optimization

7. The beam detector was based on a typical rectangular beam into which optical fiber sensors were inserted. The total cost of carrying out the beam detector along with the data acquisition equipment and the installation cost is around USD 15,000. For comparison, identical costs of mechanical WIM detectors with quartz and tensometric sensors are respectively: 32000 USD and 61000 USD [16]

8. The presented beam detector has the ability to identify the occurrence of vehicles in the field of pressure on the ground from $1000 \mathrm{~N}$ to 60000 $\mathrm{N}$. Increasing the sensitivity of the detector can be obtained by placing in the beam two additional fiber optic sensors placed symmetrically between the sensors already installed.

9. Verification tests performed on the real beam detector, next to the beam deflection and deformation measurements, should be directed at the selection of a filling gel with an inserted beam in the road lane. Selection of the gel should guarantee the stability of its physical and chemical parameters in changing atmospheric conditions.

\section{REFERENCES}

1. Burnos, P., et al. Accurate weighing of moving vehicles. Metrology and Measurement Systems. vol. 14 no. 4, 2007, 507-516.

2. Burnos P.,. Auto-calibration and temperature correction of WIM systems. Proceedings of the International conference on Heavy Vehicles: 5th International Conference on Weigh-in-Motion of Heavy Vehicles. 2008, 437-446. 
3. Cebon, D. Design of multiple-sensor weigh-in-motion systems. Journal of Automobile Engineering, Proc. I. Mech. E., 204, 1990, 133 - 144.

4. Cebon, D., Winkler CB. Multiple-Sensor WIM: Theory and experiments, Transportation Research Record, TRB, 1311, 1991, 70 -78.

5. Cole, D.J., Cebon, D. Performance and application of a capacitive strip tire force sensor. 6th International Conference on Road Traffic Monitoring and Control. IEE, London, 1992, 123-127.

6. Dolcemascolo V., Jacob B. Multiple sensor WeighIn-Motion: Optimal Design and Experimental Study. Pre-proceedings of $2^{\text {nd }}$ European Conference of Weigh in Motion of Road Vehicles, Lisbon, 1998, 129-138,.

7. Gajda J. Statistical calibration of WIM systems. Scientific Series of Rzeszów Politechnic, Electrotechnic, nr 27, 2004 (in Polish).

8. Gajda J., Burnos P. Self-calibration of the weighin-motion systems. Proceedings of XV Symposium Modelling and Simulation of Measurement Systems. 2005 (in Polish).
9. Gajda, J., et al.,. Accuracy analysis of WIM systems calibrated using pre-weighed vehicles method. Metrology and Measurement Systems. vol. 14, no. 4, 2007, 517-527.

10. Hoose N., Kunz J., 1998. Implementation and tests of quartz crystal sensor WIM system. Proceedings of 2nd European Conference „Weigh in Motion of Road Vehicle", Lisbon, 1998, 461-466.

11. Huhtala, M.,. Factors Affecting Calibration Effectiveness. Proceedings of the Final Symposium of the Project WAVE, Paris. 1999

12. Jacob B. Weigh-in Motion of Road Vehicle. Final Report of COST 323 action, ver. 3.0. 1999.

13. Mangeas, M., Glaser S., Dolcemascolo V. Neural networks estimation of truck static weights by fusing weight-in-motion data. Proc. of Eurofusion, 2000.

14. Stanczyk, D. New Calibration Procedure by Axle Rank. Proceedings of the Final Symposium of the Project WAVE, Paris, 1999

15. http://www.traffic-1.pl

16. http://przeglad-its.pl/2012/04/30/detektory-w-systemach-wim/ 